\title{
Synthesis and Characterization of Chromium(III), Molybdenum(II), Nickel(II), Palladium(II) and Platinum(II) Complexes, derived from Mixed Ligands of Pyrazole and 2,2-bipyridine
}

\author{
MAHMOUD NAJM ABID ALJIBOURI ${ }^{1 *}$, ARAF ISMAEL JABBAR ${ }^{2}$ and TAGHREED M. MUSA ${ }^{3}$
}

${ }^{1}$ Chemistry Department, College of Science, University of Mustansiriyah, Iraq.

${ }^{2}$ Ministry of Education, Directorate of Education of Anbar, Iraq.

*Corresponding author E-mail: Mahmoud_inor71@uomustansiriyah.edu.iq

http://dx.doi.org/10.13005/ojc/340343

(Received: January 16, 2018; Accepted: March 21, 2018)

\begin{abstract}
The recent paper involves the synthesis and characterization studying of chromium(III), Molybdenum(II), nickel(II), palladium(II), and platinum(II) complexes with mixed bidentate ligands namely [3,5-dimethyl-1H-pyrazole-1-carnothioamide and 2,2-Bipyridine] which has been prepared by ring closure of acetylacetone with thiosemicarbazide, in acidified by 2-normality of hydrochloric acid. The new 2-pyrazoline based ligand was identified by mass spectra, NMR and FT-IR spectra. The optimization conditions of $\mathrm{pH}$, time of reaction, and the molar ratio $(\mathrm{M}: \mathrm{L})$ were estimated in order to get the pure colored solid complexes chromium(III), molybdenum(II), nickel(II), palladium(II) and platinum(II) by the direct reactions of their metal chlorides in aqueous methanol with the ethanol solution of the ligand. The geometrical structures of the metal complexes were confirmed by measurements of electronic, IR spectra and the detection of magnetic susceptibility and molar conductivity measurements. The octahedral geometry for all complexes was suggested by the results obtained from elemental analyses and other spectral data except that palladium(II) complex which was square-planner in $[\mathrm{PdL}($ bipy $)] \mathrm{Cl}_{2}$ formula.
\end{abstract}

Key words: Transition metals complexes of 2-pyrazoline, Spectroscopic study of mixed-ligands of pyrazole, Metal chelates of 2,2-bipyridine.

\section{INTRODUCTION}

The interesting works of coordination chemistry involving the five-member rings like pyrazole have been exhibited a great powerful scaffolds in the novel drugs ${ }^{1-3}$. The poly nuclear copper(II), nickel(II) and platinum(II) complexes derived from poly dentate pyrazole ligands have described and characterized by X-ray crystallography and the biological studies revealed that the dimeric design of copper(II) complex modified the mechanism of oxidation certain types of alcohols ${ }^{4}$. As well as the mixed metal complexes of cobalt(II), copper(II) and zinc(II) derived from 3,5-dimethyl pyrazole and 8-hydroxy-quinoline was prepared and fully identified by the single(crystal.X-ray)

This is an Open Access article licensed under a Creative Commons Attribution-Non Commercial-Share Alike 4.0 International License (https://creativecommons.org/licenses/by-nc-sa/4.0/), which permits unrestricted Non Commercial use, distribution and reproduction in any medium, provided the original work is properly cited. 
diffraction and NMR spectra ${ }^{5}$. The antimicrobial study of gold(III) complexes of 4,4-dihydropyrazole1-carbothioamide have adopted ${ }^{6,7}$ and confirmed high effective against HeL4 and A549 cell lines. The increasing effective of mixed ligands incorporating with pyrazole moiety was described by the presence of $\mu$-OH, $\mu$-halide, $\mu$ - pyrazolate binuclear copper(II) complexes of 3,5-bis (pyridine-2yl) pyrazole, 3-(6-methyl pyridine-2yl-5-(pyridine-2yl) pyrazole p-11. $^{\text {. }}$. Here, the present work described the synthesis of some transition metal complexes with mixed ligands of 3,5-dimethyl-1-H-pyrazole-1-carbothioamide and 2,2-bipyridine a secondary ligand.

\section{EXPERIMENTAL}

\section{Materials and methods}

All the chemicals used for synthetic purposes were of Anala Rgrade. Solvents like methanol, nitric acid, chloroform, dimethyl sulfoxide and ethanol were purchased from Sigma Aldrich Company and used as received. Commercial methanol was purified by distillation and used. The $\mathrm{CrCl}_{3} \cdot 6 \mathrm{H}_{2} \mathrm{O}, \mathrm{MoCl}_{2} \cdot 2 \mathrm{H}_{2} \mathrm{O}$, $\mathrm{NiCl}_{2} \cdot 6 \mathrm{H}_{2} \mathrm{O}, \mathrm{K}_{2} \mathrm{PtCl}_{4}$ and $\mathrm{Na}_{2} \mathrm{PdCl}_{4}$ solutions were used without purification and were supplied from Sigma-Aldrich Company with $99 \%$ purity.

\section{Synthesis of 3,5-dimethyl-1H-Pyrazole-1- carbothioamide}

The derivative of pyrazole $(\mathrm{L})$ was prepared according to the procedure established in literature ${ }^{11}$.

A solution of $(0.91 \mathrm{~g}, 0.01 \mathrm{~mole})$ of thiosemicarbazide in $(15 \mathrm{ml})$ hot ethanol was acidified with 2-3 $\mathrm{ml}$ of concentrated $\mathrm{HCl}$, then $(10 \mathrm{ml})$ of acetylacetone was added with stirring on water bath for 1 hour. After completing the reaction through TLC technique, the mixture was kept overnight in refrigerator to afford white off precipitate was filtered off, and dried in desiccator overnight, re crystallized from hot methanol to afford $0.446 \mathrm{~g}$, $70 \%$ yield of yellow crystals of the free 2-pyrazoline primary ligand. The physical properties, and the elemental analyses were shown in Table (1).

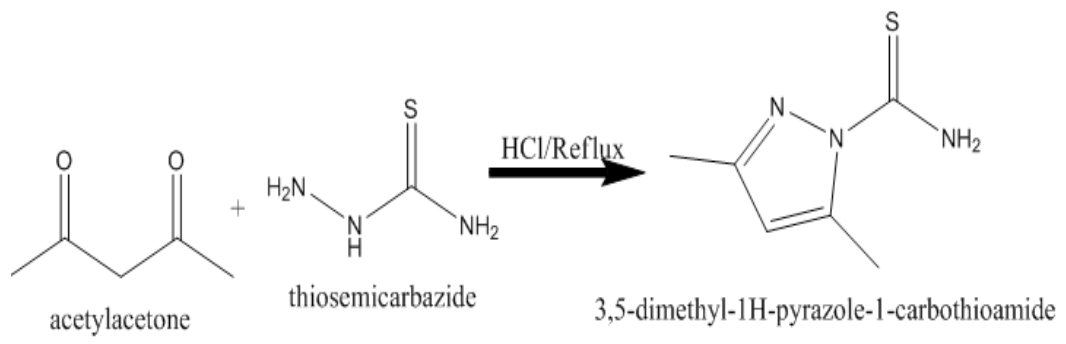

Scheme 1. Synthesis of 3,5-dimethyl-1- $H$-pyrazole-1-carbothioamide

Table1: Physical properties and elemental analyses of the $L$ ligand and metal complexes

\begin{tabular}{|c|c|c|c|c|c|c|c|}
\hline \multirow[t]{2}{*}{ Compound } & \multirow[t]{2}{*}{$\begin{array}{l}\text { Chemical formula } \\
\text { Mwt (g/mole) }\end{array}$} & \multirow[t]{2}{*}{$\begin{array}{l}\text { Colour } \\
\text { M.P. }{ }^{\circ} \mathrm{C}\end{array}$} & \multirow[t]{2}{*}{$\begin{array}{l}\text { M\% Obs. } \\
\text { (Calc) }\end{array}$} & \multicolumn{3}{|c|}{$\begin{array}{c}\text { Elemental analysis (\%) } \\
\text { Found (Calc.) }\end{array}$} & \multirow[t]{2}{*}{$\% \mathrm{~S}$} \\
\hline & & & & $\mathrm{C} \%$ & $\mathrm{H} \%$ & $\mathrm{~N} \%$ & \\
\hline \multirow[t]{2}{*}{ L } & 155 & White & - & 45.77 & 5.48 & 26.90 & 20.66 \\
\hline & $\mathrm{C}_{6} \mathrm{H}_{9} \mathrm{~N}_{3} \mathrm{~S}$ & $168-170$ & & $(46.42)$ & $(5.86)$ & $(27.07)$ & (19.60) \\
\hline \multirow[t]{2}{*}[\mathrm{CrL}^{1}(\mathrm{L})\text{bipyCl}{}_{2}]{$\mathrm{Cl}$} & 469.5 & Olive & 10.77(11.2) & 40.96 & 3.90 & 14.11 & 5.99 \\
\hline & $\mathrm{C}_{16} \mathrm{H}_{17} \mathrm{Cl}_{3} \mathrm{CrN}_{5} \mathrm{~S}$ & 299-301 & & $(93.77)$ & $(3.22)$ & $(15.00)$ & $(6.89)$ \\
\hline \multirow[t]{2}{*}[\mathrm{MoL}^{1}(\mathrm{L}^{2})\mathrm{Cl}_{2}]{} & 478.99 & Green & 19.01 & 40.20 & 3.60 & 14.68 & 6.88 \\
\hline & $\mathrm{C}_{16} \mathrm{H}_{17} \mathrm{Cl}_{2} \mathrm{MoN}_{5} \mathrm{~S}$ & $310 \mathrm{D}$ & (19.66) & (39.99) & $(3.00)$ & $(15.88)$ & $(5.88)$ \\
\hline \multirow{2}{*}[\mathrm{Ni}(\text{bipy})\mathrm{Cl}_{2}]{} & 439.02 & Brown & 12.90 & 44.55 & 3.92 & 15.89 & 7.27 \\
\hline & $\mathrm{C}_{16} \mathrm{H}_{17} \mathrm{Cl}_{2} \mathrm{NiN}_{5} \mathrm{~S}$ & $298 \mathrm{D}$ & $(13.11)$ & $(43.22)$ & $(3.11)$ & $(16.00)$ & $(6.88)$ \\
\hline \multirow[t]{2}{*}[\mathrm{PdL}\text{(bipy)}]{$\mathrm{Cl}_{2}$} & 487 & Red & 22.01 & 39.5 & 4.00 & 14.34 & 5.69 \\
\hline & $\mathrm{C}_{16} \mathrm{H}_{17} \mathrm{Cl}_{2} \mathrm{PdN}_{5} \mathrm{~S}$ & $277-279$ & $(22.90)$ & $(38.66)$ & $(3.29)$ & $(15.08)$ & $(5.22)$ \\
\hline \multirow[t]{2}{*}[\mathrm{PtL}\text{(bipy)}]{$\mathrm{Cl}_{2}$} & 576 & Orange & 33.22 & 34.10 & 2.90 & 12.14 & 5.44 \\
\hline & $\mathrm{C}_{16} \mathrm{H}_{17} \mathrm{Cl}_{2} \mathrm{PtN}_{5} \mathrm{~S}$ & $312 \mathrm{D}$ & (33.70) & $(34.00)$ & $(2.11)$ & (12.99) & (4.79) \\
\hline
\end{tabular}




\section{Synthesis of metal complexes}

Dissolve (1 mmole) of $\mathrm{CrCl}_{3} \cdot 6 \mathrm{H}_{2} \mathrm{O}(0.170 \mathrm{~g})$, $\mathrm{MoCl}_{2} \cdot 2 \mathrm{H}_{2} \mathrm{O}(0.2370 \mathrm{~g}), \mathrm{NiCl}_{2} \cdot 6 \mathrm{H}_{2} \mathrm{O}(0.456 \mathrm{~g}), \mathrm{K}_{2} \mathrm{PtCl}_{4}$ $(0.596 \mathrm{~g})$ and $\mathrm{Na}_{2} \mathrm{PdCl}_{4}(0.875 \mathrm{~g})$ in aqueous ethanol $(15-20 \mathrm{ml})$ then add gradually to stirred warmed solution of $(0.480 \mathrm{~g}, 2 \mathrm{mmole})$ of the ligand L1 in $25 \mathrm{ml}$ of methanol. After heating the solution for $15 \mathrm{~min}$., the secondary 2,2-bipydine (1.022 g, $1 \mathrm{mmole}$ ) was added gradually and the mixture was heated under reflux for three hours with adjusting the $\mathrm{pH}$ of the reaction mixture to about $(6.5-8.0)$ by drops of ammonia solution and the green crude separated out, filtered, washed several times with ethanol and distilled water. The process of reaction was followed by TLC technique with mixture of solvents (ethyl acetate: cyclohexane), Table (1).

\section{Physical measurements}

The elemental analyses (C. H. N. S) were carried out on EuroEA-Element Analyzer 3000, at College of Education of Pure Science Ibn-Al-haithum, University of Baghdad. The electronic spectra were recorded in ethanol and DMF. The FT-IR spectra of the complexes and the free primary ligand (L) were scanned in the range $(4000-400) \mathrm{cm}^{-1}$ by their thin $\mathrm{KBr}$ and $\mathrm{Csl}$ discs. The mass spectra for the prepared compounds were recorded by electron impact mass spectrometry (EIMS) using a Direct Injection Probe on a Shimadzu GCMS - QP 2010 Spectrometer, At College of Science, Department of Chemistry, Mustanseriyah University. The $1 \mathrm{H}$ and ${ }^{13} \mathrm{C}$ NMR spectra were recorded in d6-DMSO as a solvent using a Bruker DMX-500 NMR spectrometer with frequency $(300 \mathrm{MHz})$ at University of Al-Bait , Amman, Jordan.

The magnetic moments of the solid complexes were determined with Farady's method at $300 \mathrm{~K}$ temperature on Sherwood Magnetic susceptibility instrument. The estimation of metals $\mathrm{Cr}(\mathrm{III}), \mathrm{Ni}(\mathrm{II}), \mathrm{Pd}(\mathrm{II})$ and $\mathrm{Pt}(\mathrm{II})$ in solid complexes were carried out by flame atomic absorption spectroscopy through the standard addition method ${ }^{16}$ on Shimadzu Corporation Model 6809 at Ibn Cina-Center for analytical analysis and quality control.

\section{RESULTS AND DISCUSSION}

All the mixed complexes of $\mathrm{Cr}(\mathrm{III}), \mathrm{Mo}(\mathrm{II})$, $\mathrm{Ni}(\mathrm{II}), \mathrm{Pd}(\mathrm{II})$ and $\mathrm{Pt}(\mathrm{II})$ formed in solid states with high melting points and in 1:1:1 of L:bipyridine and metal ion mole ratios according to the data observed from carbon, hydrogen, nitrogen and sulfur elemental analyses. As well as the complexes are insoluble in common organic solvents like methanol, ethanol, chloroform, and sparingly soluble in acetonitrile, whereas it's solubility in DMF and DMSO was greatly, therefore the measurements of molar conductivity and electronic spectra were done in DMSO. The compositions of the prepared compounds were supported by comparison of their observed (carbon, hydrogen, and nitrogen) elemental analysis with the calculated values, Table(1).

\section{Mass spectra}

The secondary ligand according to the literature has molecular ion $\mathrm{m} / \mathrm{e}=162$ and this peak was obviously resulted from MS spectra in Figure (1). The hygroscopic effect was observed in the molecular ions of bipyridine secondary ligand.

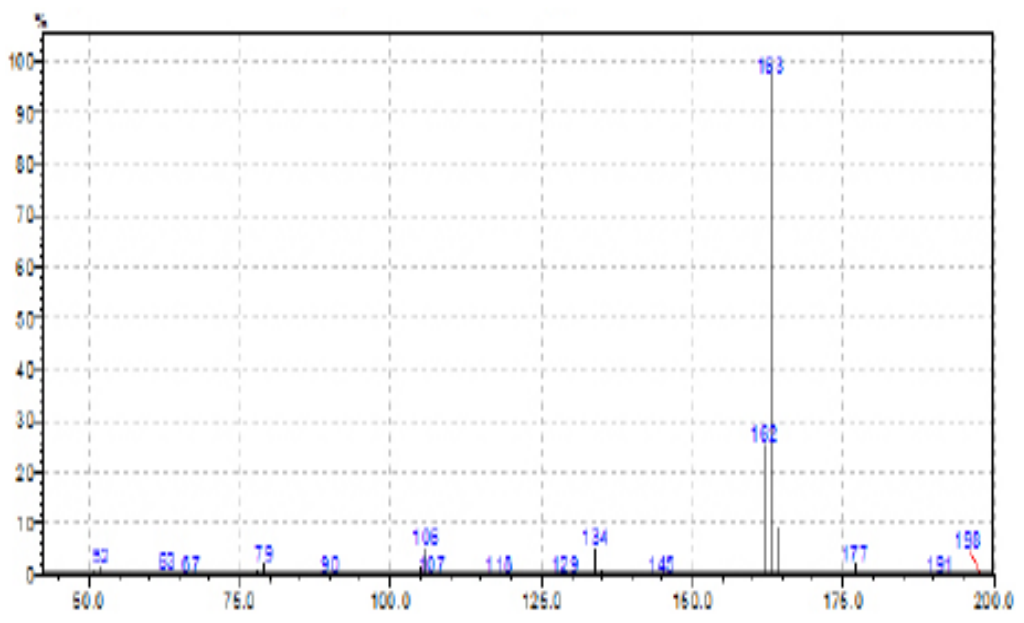

Fig. 1. Mass spectra of the secondary ligand 2,2'-bipyridine 
The Fig. (2) showed a molecular ion mle $=155$ with relative intensity of $100 \%$ indicating the base peak and high stability of $\mathrm{C}_{6} \mathrm{H}_{9} \mathrm{~N}_{3} \mathrm{~S}^{+}$. and this data supports strongly the formula and structure of the primary ligand $(\mathrm{L})$. The other fragments around $\mathrm{m} / \mathrm{e}=95$ with $65 \%$ intensity reveals the cleavage of $\mathrm{H}_{2} \mathrm{~N}-\mathrm{C}=\mathrm{S}$ moiety or cleavage of two methyl groups to afford the pyrazole ion with good stability. As well as the Fig. (3) shows the MS spectra of $\mathrm{Cr}$ (III) complex and the molecular ion $\mathrm{m} / \mathrm{e}=486$ reveals the empirical formula of the expected structure in which one mole of primary pyrazo;e ligand would be binded by coordination bond to chromium(III) ion beside one mole of a secondary 2,2-bipyridine ligand bonded through two nitrogen atoms. The fragmentations of $-\mathrm{Cl}$ in the first step of proposed mechanism in MS spectra confirms the presence of counter ion as $\mathrm{Cl}^{-1}$ and the several peaks around 380, 360 and 290 may be assigned to the cleavage of $-2 \mathrm{Cl},-\mathrm{C}_{10} \mathrm{H}_{8} \mathrm{~N}_{2}$ and $\mathrm{H}_{2} \mathrm{~N}-\mathrm{C}=\mathrm{S}$ moiety respectively.

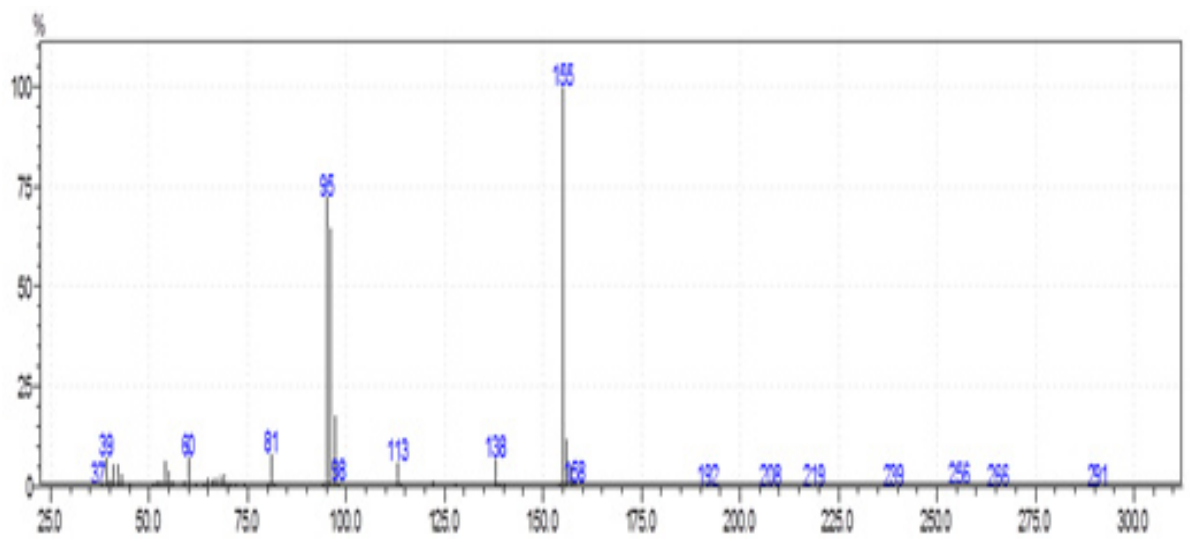

Fig. 2. Mass spectra of the primary ligand $L$

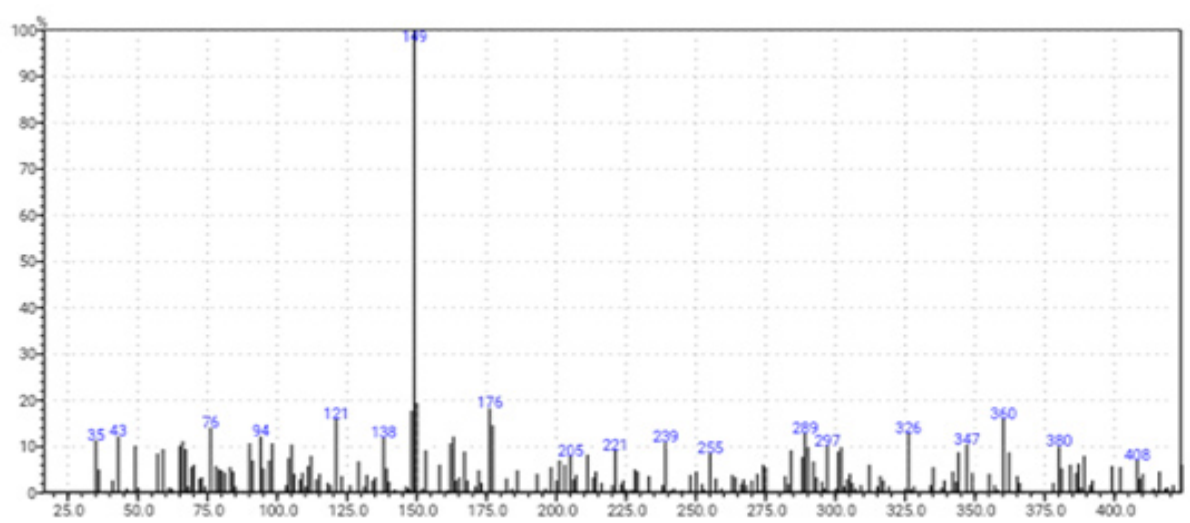

Fig. 3. Mass spectra of $[\mathrm{CrL}($ bipy $) \mathrm{Cl} 2] \mathrm{Cl}$ complex

\section{NMR Spectra}

The ${ }^{1} \mathrm{H}$ NMR spectra of the primary ligand in $\mathrm{CDCl}_{3}$ showed singlet peak at $2.49 \mathrm{ppm}$ assigning to $6 \mathrm{H}$ of two methyl groupd attached directly to pyrazole ring at 3 and 5 positions. As well as the de shielded -NH2- protons was appeared as singlet absorption around $12.187 \mathrm{ppm}$ and this confirms the ring closure of the starting materials of acetyl acetone with thiosemicarbazide in methanol solution. Furthermore the peaks in the regions 6.10 ppm and 7.65 ppm may be ascribed to $-\mathrm{CH}=\mathrm{C}$ and the tautomeric $-\mathrm{N}-\mathrm{H}$ - with $-\mathrm{S}-\mathrm{H}$ thiol form in deuterated DMSO solution, Fig. (4). As well as the carbon-13 NMR spectra of the primary pyrazole ligand in $\mathrm{CDCl}_{3}$ solvent exhibited symmetric peaks around 145, 106 and 11.20 ppm which are assigned to the resonance peaks of $-\mathrm{C}=\mathrm{S}, \mathrm{CH}=\mathrm{C}-\mathrm{N}$ - and $-\mathrm{CH}_{3}$ therefore confirms the structure of the ligand and agree well with the data observed in literature ${ }^{14}$. 


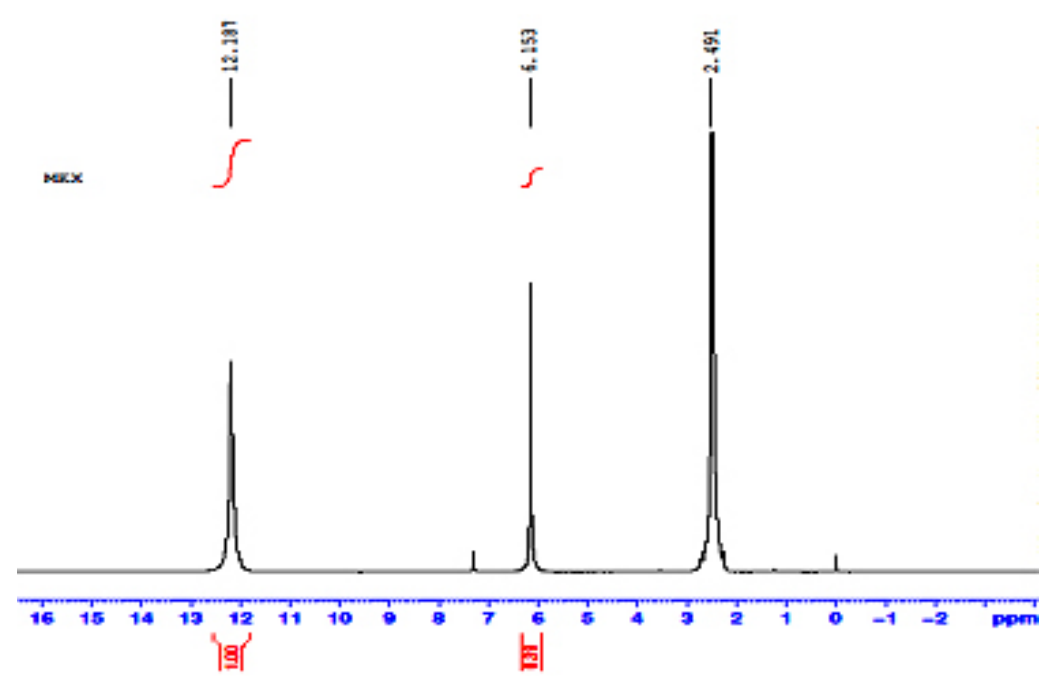

Fig. 4. $\mathrm{H}$ NMR spectra of the ligand $(\mathrm{L})$ in $\mathrm{CDCl}_{3}$ solvent

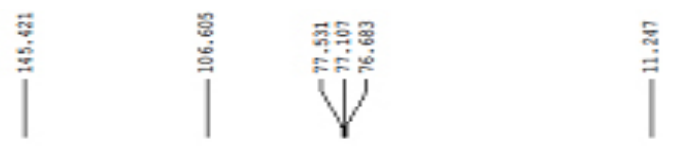

$$
\operatorname{MEx}
$$

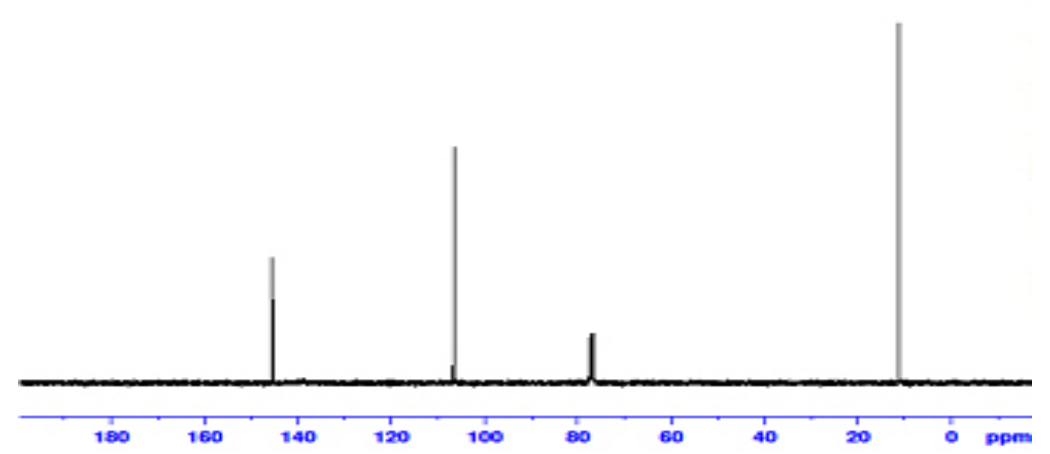

Fig. 5. ${ }^{13} \mathrm{C}$ NMR spectra of the ligand (L) in $\mathrm{CDCl}_{3}$ solvent.

\section{F.T. I. R. Spectra}

The observation of new bands around (3400-3290), and (1610-1598) $\mathrm{cm}^{-1}$ assigned to the asymmetric and symmetric modes of $-\mathrm{NH} 2$ - and the absorptions of imine- $\mathrm{C}=\mathrm{N}$ - of pyrazole ring respectively ${ }^{13,14}$. It is obviously that the FT-IR spectra of all metal complexes showed remarkable changes in the positions and intensities of the imine- $\mathrm{C}=\mathrm{N}-,-\mathrm{C}=\mathrm{S}$ and $-\mathrm{NH}$ - groups which confirmed the participation of the nitrogen and sulphur atoms of pyridyine and carbothioamide in $\mathrm{N} 2-$ and $\mathrm{N} 1$ - in coordination with the metal ions ${ }^{16,17,18}$. The appearance of strong absorptions in the regions
$1530-1518 \mathrm{~cm}^{-1}, 1480-1420$, and 13200-1240 $\mathrm{cm}^{-1}$ may be assigned to $-\mathrm{C}=\mathrm{N}-$ and $-\mathrm{C}=\mathrm{C}$-and $-\mathrm{C}=\mathrm{S}$ moieties of pyrazoline and thioamide groups respectively, then revealed the formation of five-member ring with ions of chromium(II), molybdenum(II), palladium(II), and platinum(II). The broad bands around $3500-3200 \mathrm{~cm}^{-1}$ besides the bending of coordinated water molecules in the regions $1560-1550 \mathrm{~cm}^{-1}$, and $845-822 \mathrm{~cm}^{-1}$ supported the $-\mathrm{OH}$ coordinated by water in the inner sphere of metal complexes ${ }^{17}$. Furthermore, the infrared spectra of the nickel(II) complex showed weak to medium bands around $250-375 \mathrm{~cm}^{-1}$ supporting 
$\mathrm{Zn}-\mathrm{Cl}$ bonds. The lower frequency regions of IR spectra of all complexes recorded weak bands around (455-560) $\mathrm{cm}^{-1}$ and (400-388) $\mathrm{cm}^{-1}$ that are attributed to $\mathrm{M}-\mathrm{N}$ and $\mathrm{M}-\mathrm{S}$ bonds respectively ${ }^{17,18}$. The data obtained from FT-IR spectra investigated the bidentate behavior of the ligand through two nitrogen atoms of pyrazoline and pyridine rings, thereby gives strong proof for the metal complexes formation and kinetic stability of the five-member ring chelate with the selected bivalent metals ${ }^{18}$.

Table 2: IR spectra $\mathrm{n} \mathrm{cm}^{-1}$ of the ligand $(L)$ and it's metal complexes

\begin{tabular}{|c|c|c|c|c|c|}
\hline $\begin{array}{l}\text { Compound } \\
\mathrm{L}\end{array}$ & $\begin{array}{c}v(\mathrm{~N}-\mathrm{H}) \mathrm{cm}^{-1} \\
3420,3180(\mathrm{~m})\end{array}$ & $\begin{array}{c}v(\mathrm{C}=\mathrm{N}) \mathrm{cm}^{-1} \\
1600-1596(\mathrm{~s})\end{array}$ & $\begin{array}{c}v(\mathrm{C}=\mathrm{S}) \mathrm{cm}^{-1} \\
1254(\mathrm{~m}) \\
870(\mathrm{~s})\end{array}$ & $\begin{array}{c}v(\mathrm{M}-\mathrm{N}) \\
-\end{array}$ & $\begin{array}{c}v(\mathrm{M}-\mathrm{S}) \\
-\end{array}$ \\
\hline Cr-L & 3390(br) & 1533(sh) & 1238(m) & $488(w)$ & $412(w)$ \\
\hline Mo-L & $3420,3100(\mathrm{~m})$ & 1549(s) & $\begin{array}{l}1230(\mathrm{~s}) \\
855(\mathrm{~m})\end{array}$ & $422(m)$ & $388(w)$ \\
\hline $\mathrm{Ni}-\mathrm{L}$ & $3217(\mathrm{~m})$ & 11580(s) & $\begin{array}{l}1225(m) \\
865(m)\end{array}$ & $500(w)$ & $435(w)$ \\
\hline Pd-L & $3333(\mathrm{br})$ & $1575(\mathrm{~s})$ & $\begin{array}{l}1222(\mathrm{~s}) \\
870(\mathrm{~s})\end{array}$ & $512(\mathrm{~m})$ & $410(w)$ \\
\hline Pt-L & $3197(\mathrm{~m})$ & $1528(s)$ & $\begin{array}{l}1240(m) \\
827(m)\end{array}$ & $560(w)$ & $450(\mathrm{~m})$ \\
\hline
\end{tabular}

br=broad, $\mathrm{m}=$ =medium, $\mathrm{s}=$ strong, $\mathrm{sh}=$ shoulder and $\mathrm{w}=$ weak.

UV-Visible spectra and magnetic measurements

The UV-Vis spectrum of the free ligand of pyrazole-carbthioamide in methanol displayed two peaks at 50000 and $32258 \mathrm{~cm}^{-1}$ ascribing to the moderate energy $\pi \rightarrow \pi^{*}$ and $n \rightarrow \pi^{*}$ respectively associating with the functional groups of transition $\mathrm{C}=\mathrm{N}-$ and $-\mathrm{C}=\mathrm{S}$ moiety ${ }^{17,18}$. The solutions of metal complexes in DMF solvent (10-3 M) display spinallowed absorptions in the visible regin assigning to the $d-d$ spectra of the metal ions involved in the structure of the prepared complexes. The green solution of $\mathrm{Cr}$ (III) complex showed two weak bands around 10527, $16666 \mathrm{~cm}^{-1}$ supporting the octahedral environment around $\mathrm{Cr}(\mathrm{III})$ ion. As well as the intense peak at $28985 \mathrm{~cm}^{-1}$ is belonged to LMCT then confirm the proposed structure of $\mathrm{Cr}(\mathrm{III})$ complex ${ }^{20,21}$. By the same way the molybdenum(III) complex in DMF showed there bands around 13333, 20832 and $31055 \mathrm{~cm}^{-1}$ confirming the $d-d$ spectra of $\mathrm{Mo}$ (II) octahedral complexes ${ }^{20,21}$. The paramagnetic properties of $\mathrm{Cr}(\mathrm{III})$ and $\mathrm{Mo}(\mathrm{II})$ complexes with magnetic momentums values (3.8-3.90) BM assist in the elucidation their structures ${ }^{21-23}$. As well as the olive solution of nickel(II) complex in DMF exhibited two spin-allowed transitions at 12048 and $27027 \mathrm{~cm}^{-1}$ which supports the high-spin of 3d8 configuration. The orange and yellow solutions of palladium(II) and platinum(II) complexes in DMF displayed (29761-36363) $\mathrm{cm}^{-1}$ and (17543 -23094 $\mathrm{cm}^{-1}$ assigning to the spin-allowed of $\left(\mathrm{n}^{-1}\right) \mathrm{d} 8$ configuration of the type $1 \mathrm{~A} 1 \mathrm{~g} \rightarrow 1 \mathrm{~B} 1 \mathrm{~g}$ and $1 \mathrm{~A} 1 \mathrm{~g} \rightarrow 1 \mathrm{~B} 2 \mathrm{~g}$ respectively ${ }^{24}$. The diamagnetic properties of $\mathrm{Pd}(\mathrm{II})$ and $\mathrm{Pt}(\mathrm{II})$ complexes indicates the low-spin state for the square-planner $\left(\mathrm{n}^{-1}\right) \mathrm{d} 8$ configuration then ascribed their electronic transitions in the UV-Visible 25,26 .

Table 3: Electronic spectra ,molar conductivity and magnetic moments of the complexes

Compound $\lambda \max (\mathrm{nm}) \cup \mathrm{cm}-1 \quad \Lambda \mathrm{ohm}^{-1} \quad \mu \mathrm{B} \cdot \mathrm{M}$ $\mathrm{cm}^{2} \cdot \mathrm{mol}^{-1}$

\begin{tabular}{|c|c|c|c|c|}
\hline $\mathrm{L}$ & 250 & 50000 & - & - \\
\hline 310 & 32258 & & & \\
\hline \multirow[t]{3}{*}{ Cr-L } & 600 & 10527 & 55 & 3.88 \\
\hline & 450 & 16666 & & \\
\hline & 300 & 28985 & & \\
\hline \multirow[t]{3}{*}{ Mo-L } & 750 & 13333 & 12 & 3.9 \\
\hline & 480 & 20832 & & \\
\hline & 322 & 31055 & & \\
\hline \multirow[t]{2}{*}{$\mathrm{Ni}-\mathrm{L}$} & 835 & 12048 & 22 & 3.22 \\
\hline & 370 & 27027 & & \\
\hline \multirow[t]{2}{*}{ Pd-L } & 336 & 29761 & 89 & 0 \\
\hline & 275 & 36363 & & \\
\hline \multirow[t]{2}{*}{ Pt-L } & 570 & 17543 & 17 & 0 \\
\hline & 433 & & 23094 & \\
\hline
\end{tabular}

$\Lambda=$ molar conductance in DMSO solutions of $0.001 \mathrm{M}$ concentration. 


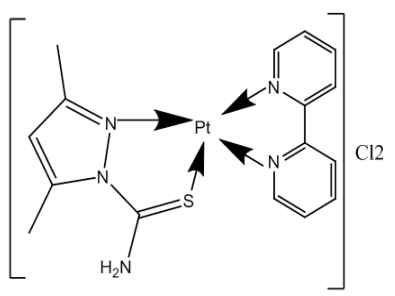

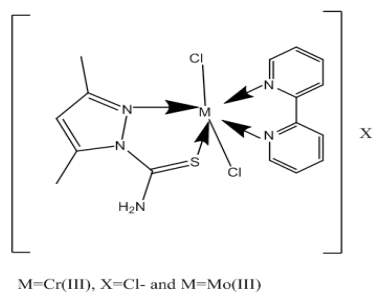

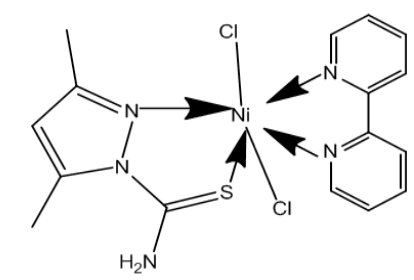

Scheme 3. Geometrical structures of the prepared metal complexes

Effect of $\mathrm{pH}$ on the formation of metal complexes

The UV-Vis spectra of Molybdenum(II)-ligand mixed solution with a concentration range of $\left(2^{*} 10-3-1^{*} 10^{-3}\right) \mathrm{M}$ were studied. The concentration of $\left(2^{*} 10^{-3}\right) \mathrm{M}$ was obeyed the Lambert-Beer's law and showed a clear intense color. A straight line, with correlation factor $(r=0.98)$, was obtained when the absorbance plotted against the molar concentration, as well as the investigation of 2:1 molar ratio of the ligand to metal ion in methanolic solution after adjusting the acidity of mixture and the absorption of $d-d$ regarding molybdenum(II)-L complex at 835 $\mathrm{nm}^{27}$.

\section{CONCLUSION}

According to the results obtained from elemental analyses, proton nmr, IR, mass spectra and magnetic moments the new derivative of 2-pyrazoline behaved as bi dentate ligand toward the chromium(III), molybdenum(II), nickel(II), palladium(II) and platinum(II) ions. The all complexes were isolated in the solid state after optimization the conditions of time, acidity, and the molar ratio. The active sites of the ligand in bonding with the metal ions are the two atoms of nitrogen $2 \mathrm{~N}$ of pyrazole ring and sulfur atom of thiocarbamide moiety then proposing a kinetic stable five member ring and the suggested geometry of the chromium(III) and molybdenum(II) were octahedral in the formulas $\left[\mathrm{Cr}(\mathrm{L})(\right.$ bipy $\left.) \mathrm{Cl}_{2}\right] \mathrm{Cl}$ and $\left[\mathrm{Mo}(\mathrm{L})(\right.$ bipy $\left.) \mathrm{Cl}_{2}\right]$ respectively. However, the square-planner geometry was obtained for palladium(II) and platinum(II) complexes with $[\mathrm{ML}($ bipy $)] \mathrm{Cl}_{2}$ formula.

\section{ACKNOWLEDGMENT}

We are so grateful to the members work in the service laboratories at Chemistry Department, College of Science, University of Mustansiriyah for facilitating the measurements of the FT-IR, UV-Visible, mass spectra, magnetic susceptibility and the molar conductivity. As well as, we appreciated the efforts of Al-Bait university for analysis of NMR spectra.

\section{REFERENCES}

1. T. L. Jacobs, in R. C. Elderfield, Ed., Hetrocyclic compounds, John Wiley and Sons, Inc., New York., 1957, 45, 5.

2. Sharma, P. K., Kumar S., Kumar. P., Kaushik. P., Daushik, D., Dhingra, Y., Aneja, K. R., Eur. J. Med. Chem., 2010, 45, 2650-2655.

3. Saugata, K. Atanu, J. Kinsuk, D. Sangita, R. Sudipta, C. James, A. Arnold, L. Rheingold, S. Kumar, K. Polyhedron., 2011, 30, 2801-2808.

4. Guo-Fang Zhang, Qiu-Ping Zhou, YinLi Dou, Mai-Hua Yin and Yao Wang " Synthesis, structural characterization and catalytic activities of dicopper(II) complexes derived from tridentate pyrazole-based $\mathrm{N}_{2} \mathrm{O}$ ligands" Appl. Organometal. Chem., 2007, 21, 1059-1065.

5. Saugata, K. Atanu ,J. Kinsuk ,D. Sangita, R. Sudipta, C. James, A. Arnold, L. Rheingold and S. Kumar, K." Synthesis, crystal structure, spectroscopic and photoluminescence studies of manganese(II), cobalt(II), cadmium(II), zinc(II) and copper(II) complexes with a pyrazole derived Schiff base ligand, Plyhedron., 2011, 30, 2801-2808.

6. Frankiine K. Keter, Stonard Kanyanda, Syvester S. L. Lyantagaye, James Darkwa, D. Jasper G.Rees and Mervin Meyer " In vitro evaluation of dichloro-bis(pyrazole) 
palladium(II) and dichloro-bis(pyrazole) platinum(II) complexes as anticancer agents", Cancer Chemother Pharmacol., 2008, 63,127-138.

7. Shuxiang, W.Wenquing, S.Hongdong, L.Cui, L.Wang, K.Zhang, J.Eur. J. Med. Chem., 2011, 46, 1914-1918.

8. Attila, K.Denes, N.Gyorgy, P.Katalin, M.Vukadin, M.Zeljko, J.Ivan, R.Judith, H.Zoran, D.Gerald, G. J.Chem., 2005, 29,833-840.

9. Bogulmila,Krysztof,S.Katarzyna,M.Kamila,K. Malgorzata,C.Keppler,B.Budzsz,E. Med. Chem. Res., 2013, 22, 2395-2402.

10. Kishwar,S.W.Waseem,L.Mohamad,H.Ming, J.Mohamad,Imran, A. Future Med.Chem., 2013, 5(2), 135-146.

11. Z.Marczenko, "Spectrophotometric determination of elements", John Wiley and Sons, 1st Ed.1976.

12. Sau, D. K. Butcher, R.J. Chudhuri and S. Saha, N.'spectroscopic, structural and antibacterial properties of copper (II) complexes with bio-relevant 5-methyl-3-formyl pyrazol-N(4)benzyl-N(4) methyl thiosemicarbazone" Mol. Cell. Biochem., 2003, 253, 21-29.

13. Jons, J. Sanchez, F. J. Labarta, A. Casabo, J. Texido and F. Caubet, A. "Mixed bridged, dinuclear copper(II) complex with dinuclearingpyrazole derived ligand" Inorg. Chim. Actc.,1993, 208, 167-171.

14. Luisa, M.D.Martinsa, R.S.Armandao, J.Pombeira and L. Water-Soluble C-Scorpionate Complexes - Catalytic and Biological Applications, Eur. J. Inorg. Chem., 2016, 2, 2236-2252.

15. Hiroshi Maruoka, Sho Nishida, Nobuhiro Kashige, Yuki Yoshimura, Masahiko Omori, Ryoko Tomita, Eiichi Masumoto, Fumi Okabe,Fumio Miake, Kenji Yamagata and Toshihiro Fujioka" Synthesis and Biological Activity of Some New Pyrazole Copper(II) Complexes, J. Heterocy. Chem., 2012, 49,1218-1223.

16. Silverstein, R.M.Webster and F. Kienle, D.J. "Spectrometric Identification of Organic Compounds", John Wiley \& Sons, USA. New York,1984.

17. Hai-Bin, S.Shun-Jun and J. Bing, B. "Studies on transition metal ions recognition properties of 1-(2-benzothiazole)-3-(2-thiophene)-2- pyrazoline derivatives, Dyes \& Pigm., 2007, 73, 394-396.

18. Saled M. Khalil "Synthesis, Spectroscopic and Magnetic studies on metal complexes of 5-methyl-3-(2-hydroxy phenyl pyrazole", J. Coord. Chem., 2003.

19. Mishra, R.C., "synthesis and physicchemical studies of some novel mixedligand cyanonitrosyl\{CrNO\}5 complexes of chromium(III) with 2-pyrazoline-5-one derivatives", Transition Met. Chem. 1987,12, 551-552.

20. Nakamato K."Infrared\&Raman spectra of Inorganic and Coordination Copounds"5th. Edn.John \&Wiley Sons, New York,1998, 183-187.

21. Sian C. Davies, Marcus C. Durrant, David L. Hughes, Abbas Pezeshk, Raymond L. Richards," Coordination chemistry of a pyrazoline derived from 2,4-pentanedione bis(4-methylthiosemicarbazone) Crystal structure of the pyrazoline and evidence formetal-mediated ring opening", J. Chem. Research, 2011,100-103.

22. Huheey, J. E; "Inorganic Chemistry, Principles of Structure and Reactivity" Harper. International 51 Edittion; Maryland,1994.

23. Green Wood, N. N.Earnshow, A. "Chemistry of the Elements", Ed. J. Wiley, Sons. Inc.New York,1998.

24. D. Sutton "Electronic Spectra of Transition Metal Complexes "McGraw Hill, New York, 1968.

25. Saugata, K. Atanu ,J. Kinsuk ,D. Sangita, R. Sudipta, C. James, A. Arnold, L. Rheingold, S. Kumar, K." Synthesis, crystal structure, spectroscopic and photoluminescence studies of manganese(II), cobalt(II), cadmium(II), zinc(II) and copper(II) complexes with a pyrazole derived Schiff base ligand, Plyhedron, 2011, 30, 2801-2808.

26. Attila, K.Denes, N.Gyorgy, P.Katalin, M. Vukadin, M. Zeljko, J. Ivan, R. Judith, H. Zoran and D. Gerald, G. "Structural, spectroscopic and computational studies of the $\mathrm{HgL}_{2} \mathrm{Cl}_{2}$ complex ( $L=3,5$-dimethyl-1-thiocarboxamide pyrazole) and the crystal structure of L New" J. Chem. 2005, 29, 833-840.

27. Frankiine K. Keter, StonardKanyanda, Syvester S. L. Lyantagaye, James Darkwa, D. Jasper G.Rees and Mervin Meyer "In vitro evaluation of dichloro-bis(pyrazole) palladium(II) and dichloro-bis(pyrazole) platinum(II) complexes as anticancer agents", Cancer Chemother Pharmacol., 2008, 63, 127-138. 